\title{
DIFFICULTIES IN MANAGING DIVERSITY IN GEORGIAN EDUCATIONAL ORGANIZATIONS
}

\author{
Ketevan Goletiani ${ }^{1}$, Zurab Mushkudiani ${ }^{2}$, Ekaterine Gulua ${ }^{3}$, Natela Janelidze ${ }^{4}$ \\ ${ }^{1,2}$ Batumi Navigation Teaching University, Batumi, Georgia \\ ${ }^{3}$ Ivane Javakhishvili State University, Tbilisi, Georgia \\ ${ }^{4}$ Akaki Tsereteli State University, Kutaisi, Georgia
}

e-mails: ${ }^{1}$ k.goletiani@bntu.edu.ge, ${ }^{2}$ z.mushkudiani@bntu.edu.ge, ${ }^{3}$ ekaterine.gulua@tsu.ge,

${ }^{4}$ natela.janeliddze@atsu.edu.ge

Received: 17 December 2020; Accepted: 20 February 2021 Published: 01 May 2021

\begin{abstract}
The twenty-first century can be boldly called the century of globalization. In the process of globalization, the study of the differences between the peoples of different countries, based on the study of labour diversity, becomes relevant. Due to the fact that the current socio-economic development of Georgia is not so favourable, Georgia needs to occupy a certain niche in different markets of the world, for which it is necessary to introduce many innovative models in all spheres, including management, and this is a difficult process considering various factors.

Objectives: To increase the productivity of human capital, certain processes need to be implemented. One of the first steps is to set up a team within the company, each member of which feels that he/she is an important part of the main goal or strategy of the company and that he/she has an important role to play, the responsibility for successful implementation as a common and team process.

Methods/Approach: Both qualitative and quantitative studies carried out in three educational institutions in Georgia. Results: As a result of the main analysis of the study and its judgment, the main measures for improving the efficiency of a diverse workforce are outlined and a concluding part is offered.

Conclusions: Difficulties of teamwork that take place in Georgian companies are discussed; Also, the focus is made on the problems identified in the personnel management process and the mechanisms for overcoming them.
\end{abstract}

Keywords: labour, workforce diversity, company management, cognitive dissonance, discrimination

JEL classification: J5, J70, J71, J83, M1

Citation:

Goletiani, K., Mushkudiani, Z., Gulua, E., Janelidze, N. (2021). Difficulties in managing diversity in Georgian educational organizations. Access to science, business, innovation in digital economy, ACCESS Press, 2(2): $123-137$. https://doi.org/10.46656/access.2021.2.2(1)

\section{INTRODUCTION}

Organizations are complex adaptive systems. Since the environment in which they exist is constantly evolving and changing, they must keep pace with the changes. In a world that is becoming more and more complex socially, politically, and economically, the adaptation process never ends. Organizations have to work in an environment where components are sometimes so closely interconnected that changing one of them may have an unpredictable and uncontrollable effect on the other. Research shows that this complexity is the biggest challenge for today's world leaders. (Mushkudiani, Gechbaia, Gigauri \& Gulua, 2020) Management in the 
modern environment becomes more humane and human-centred (Gigauri, 2021; Gulua, 2020A). It is also important to identify management difficulties in the context of workforce diversity and to develop ways to ensure them (Gulua, 2020B; Gigauri, 2020A). The topic is important as the diversity of the workforce is one of the most difficult and delicate issues for the management of any organization.

Important issues related to the diversity of the workforce, such as emotions, attitudes and job satisfaction, are very interesting and deserving of attention. Organizational commitments and job satisfaction trends that are directly related to work performance (Shonia, Mushkudiani, Shalamberidze \& Janelidze, 2018) are relevant and improving them is a number one priority for any manager.

\section{Methodology}

The purpose of the study was to examine the attitudes of employees towards diversity management in their respective educational institutions.

Both qualitative and quantitative studies have been carried out in three educational institutions in Georgia. The anonymous questionnaire survey was used as the main method of quantitative study through a preprepared questionnaire. The population of the survey was 719 people; 425 respondents filled in the questionnaire.

\section{Results}

Organizations today most of all need successful leaders at all levels of management, as well as effective followers to help them achieve their goals. Followers can no longer shrug off responsibility and shift it onto someone else. Their duty is not to obey the leaders without objecting, but to defy them if necessary. At the same time, they must constantly accumulate new ideas and show creativity in the process of activity (Gechbaia \& Mushkudiani, 2016) effective followers must respect the leaders and constantly keep the main goal in mind - to focus on successful collaboration with the leader in order to achieve the main goals and mission of the organization. Only this kind of effective collaboration can yield the best outcomes (Faresashvili \& Keshelashvili, 2010)

One of the most important challenges organizations face is getting used to different people. We use the term "workforce diversity" to describe this problem. Globalization is about differences between the peoples of different countries, while the diversity of the workforce discusses the differences between people in those countries.

Workforce diversity has become a pressing issue for management as organizations gradually become more diverse in terms of gender, age, race, ethnicity, sexual orientation, or other characteristics. Members 
of diverse organizations are: women, persons of color, people with disabilities, the elderly, representatives of sexual minorities, etc (Robbins \& Judge, 2008)

Diversity is at the core of every organization. A deep interest in diversity should be a central priority in all aspects of doing business. Diversity leads to differences, and differences, along with generating new ideas and many important benefits, create potential relationship problems. This is an important challenge and cannot be denied, but it is also very important that diversity includes a huge potential of opportunity.

In Canada and Australia, for example, managers have to adjust to the large influx of Asian workers. In South Africa, blacks are gradually getting employed in important technical and management services. In Japan, women who have long worked in low-paying, temporary jobs have taken up managerial positions. With regards to this issues the EU Trade Cooperation Agreement, which opened the borders for most Western European countries, has had a significant impact on these issues, which in turn has led to an increase in the diversity of the workforce in organizations operating in the EU member states.

Managers have to change their stigmas, change their principles, understand the differences between employees and act in accordance with these differences in order to retain employees and at the same time increase their productivity. This change means, for example, providing various trainings and improving benefit programs to meet the different interests of staff. Diversity, when managed properly, can foster creativity and innovation in organizations, and improve decision-making by taking into account different perspectives on problems (Mushkudiani \& Dzotsenidze, 2019). When diversity is not properly managed, the likelihood of labor outflow, communication difficulties, and conflict between people increases.

If modern managers fail to realize the fact that they should generally try to improve quality and productivity only with employees, then they should understand the unintended consequences. Therefore, they should not only become a key force in implementing change, but also be actively involved in planning for that change.

Workforce diversity can be viewed in both demographic as well as social and cultural contexts. Its main categories include the following (Mullins, 2007).

- Gender. In most countries of the world, the share of women in the labor force is increasing. Organizations should ensure a hiring and employment policy that creates equal opportunities and access for all people, regardless of gender.

- Race. Organizations must ensure policies that create equal opportunities and access for all people, regardless of race. 
Nationality. The share of immigrants or workers from countries whose native languages are different is increasing.

Age. Recent statistics show that more and more employed people are trying to work until reaching retirement age. Organizations cannot discriminate against employees on the basis of age, and they must meet the needs of older workers.

- Disability. Organizations need to ensure that services and jobs are accessible to people with physical disabilities. However, in this regard, we think that the state should also contribute in terms of introducing certain incentives.

- Family partners. Gradually more gays and lesbians are demanding the same rights and benefits for their partners at work that organizations offer to employees in traditional marriages.

- Religion. - In organizations, the governing body must give due consideration to both Christian and non-Christian employees of different confessions (Judaism, Islam, Hinduism, Buddhism), as well as their customs, rituals and holidays, as well as their appearance and dress. Organizations must ensure that these employees are not treated differently because of their appearance and activities, so that they do not perceive themselves as victims of discrimination.

- Customer diversity - Diversity management implies equal treatment of diverse customers. Today, the majority of the workforce in developed countries works in the service sector. For example, $80 \%$ of the US workforce is employed in the service industry. In the UK, Germany and Japan, the percentages are 69, 68 and 65\%, respectively. Service sectors include: technical support workers, catering staff, sales agents, waiters, babysitters, car repairmen, consultants, credit bureaus, financial advisers, and flight attendants. All of these services require frequent interaction with customers. Many organizations have failed because their employees failed to meet customers' needs. So, the management needs to create an appropriate culture of consumer demand. Organizational behavior can help managers create a culture in which employees can identify the following qualities: kind-heartedness and attention, accessibility, knowledge, quick response to customer requests, willingness to act in a way that pleases customers regardless of their status.

Another term - organizational climate - is a general understanding of what an organization is in terms of management policies and practices. In some organizations, communication between managers and employees is open, while in others managers are distance and communication is limited.

How organizational culture and climate affect the members of the organization depends on how the 
internal environment of the organization and the individual characteristics of the member "fit" each other. People who adapt well to culture and climate are more self-confident and experience satisfaction. Others may become victims of stress, aggressive, or even leave the organization.

An important aspect of diversity management is the protection of the principle of justice, the restriction of discrimination, the protection of equal human rights both in employment and in recruitment (Gigauri, Gulua \& Mushkudiani, 2020).

When hiring, equal rights management eliminates discrimination. The decision to hire should not be discriminatory, unless its purpose is to exclude any group protected by law or to create obstacles to it. A set of measures needs to be developed to address the discrimination fact already happened or to eliminate the statistical imbalance in the workforce.

Discrimination during hiring in the United States is prohibited under the Civil Rights Act of 1964. This act prohibits discrimination in hiring, promotion, discharge, pay, fringe benefits, job training, classification, referral, and other aspects of employment, on the basis of race, color, religion, sex or national origin. Relevant decisions in the U.S. must be substantiated by both federal, state, provincial, and local laws, as well as case law.

In any type of organization, the foundation of an organizational behavior system is made up of individuals who have combined their efforts to create it (e.g., company owners) as well as the managers who run its operations. Diversity management is based on the organizational behavior philosophy (theoretical model) of the organization's management, which includes a set of assumptions and beliefs of its leaders and managers about the real state of the company, its manufacturing activity and possible ideal system.

Labour Code of Georgia provides that labour and pre-contractual relations shall prohibit any type of discrimination including when posting a job vacancy and at the selection stage due to race, skin colour, language, ethnicity or social status, nationality, origin, material status or position, place of residence, age, sex, sexual orientation, marital status, handicap, religious, public, political or other affiliation, including affiliation to trade unions, political or other opinions.

Guiding principles for the regulation of labour relations are such important documents as: Universal Declaration of Human Rights by the United Nations General Assembly, adopted on 10/12/1948, European Convention on Human Rights adopted by the Council of Europe on 4 November 1950; European Social Charter of 1961 (Council of Europe, 26/02/1961); United Nations Covenant on Civil and Political Rights 
(ICCPR) of 16 December 1966, and International Covenant on Economic, Social and Cultural Rights (United Nations, 16/12/1966).

\section{Discussion}

We took an interested in how equally women and men are treated in the workplace in Georgia. We studied their average nominal wages. A study of official data from the National Statistics Office of Georgia showed that the average salary of women lags behind that of men.

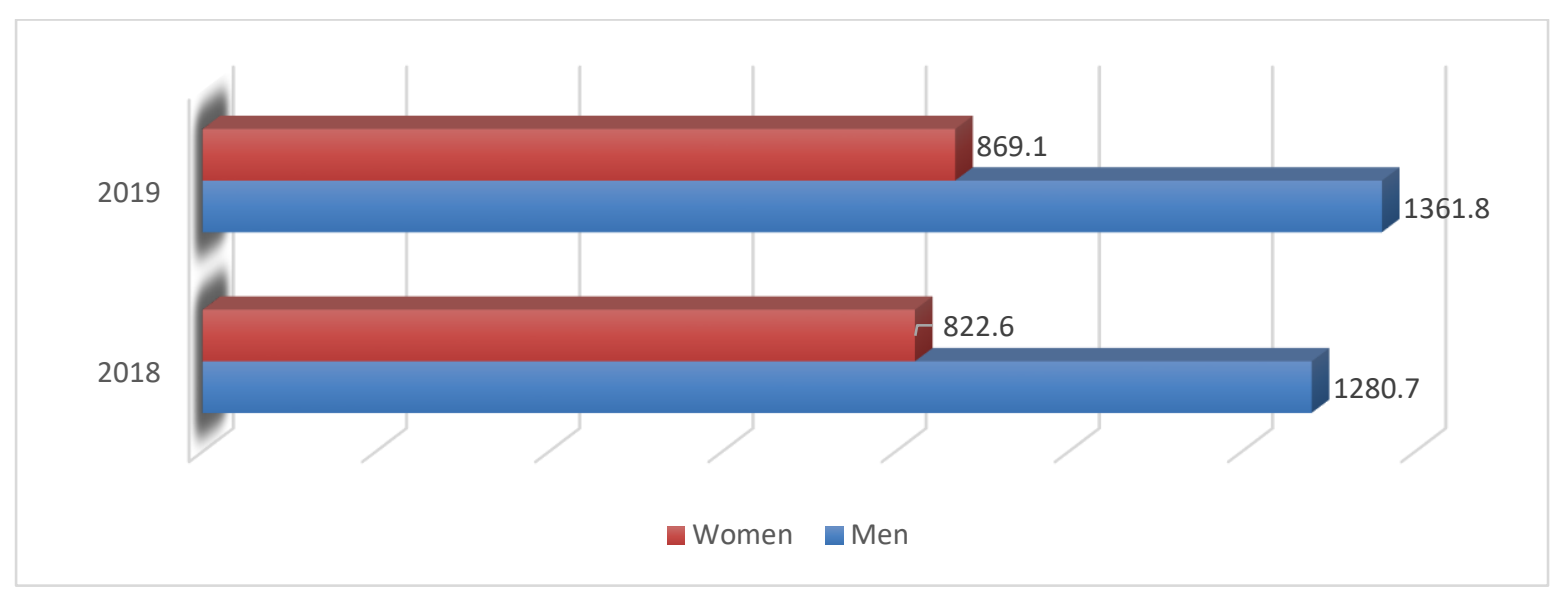

Figure 1. Average Monthly Wages by Sex (Gel)

Source: National Statistics Office of Georgia

The average monthly wage for men is $\$ 377$ while the average wage for women is $\$ 242$.

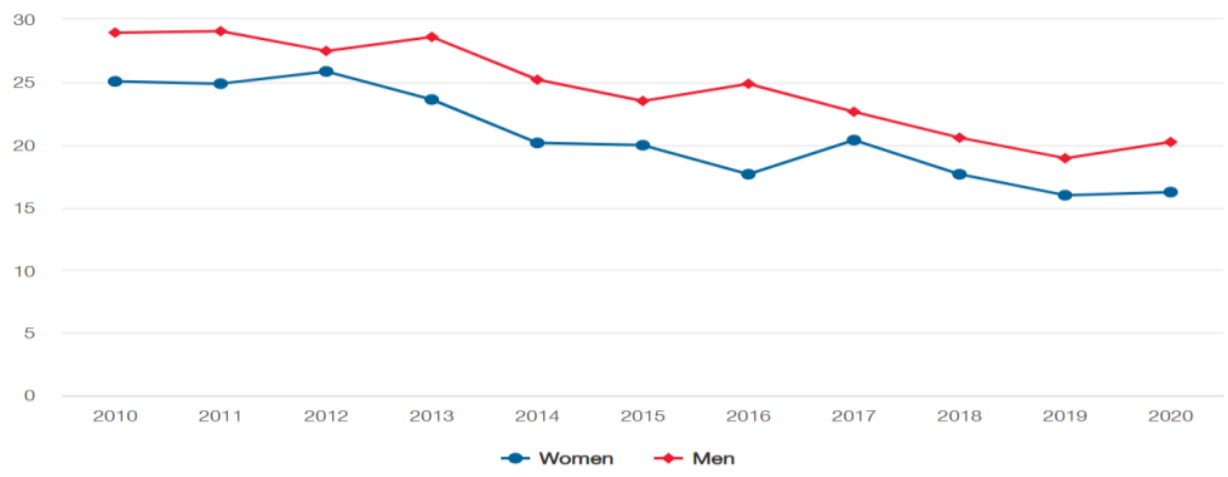

Figure 2. Unemployment Rate by Sex (\%)

Source: National Statistics Office of Georgia

According to official statistics, the unemployment rate among women is lower than the unemployment rate among men. One of the reasons for this reality is the low price of women's labor (figure 2). 
A detailed analysis of the labour force by sex shows that as of the fourth quarter of 2020 , the population of women over the age of 15 exceeds the number of men, although the active labour force shows a larger number of men $62.04 \%$ and women $39.47 \%$; The female labour force is $27.27 \%$ lower than the male active labour force. $60.53 \%$ of the female population is outside the labor force, that is 1.8 times more $(972.2$ thousand women) compared to the number of men outside the labor force (553.4 thousand men). Against the background of the above indicators, the fact that unemployment among women lags behind male unemployment is not a good indicator to consider the general condition as healthy (see Table 1).

Table.1 Labour force Indicators by Sex

\begin{tabular}{|c|c|c|c|c|c|c|}
\hline \multicolumn{7}{|c|}{ Labour Force Indicators by Sex } \\
\hline Thousand persons & \multicolumn{2}{|c|}{$4 Q-2018$} & \multicolumn{2}{|c|}{$4 Q-2019$} & \multicolumn{2}{|c|}{$4 Q-2020$} \\
\hline & $\begin{array}{c}\text { Wome } \\
\text { n }\end{array}$ & Men & $\begin{array}{c}\text { Wome } \\
\text { n }\end{array}$ & Men & $\begin{array}{c}\text { Wome } \\
\text { n }\end{array}$ & Men \\
\hline Total $15+$ population & 1614.5 & 1408.9 & 1607.5 & 1424.4 & 1606.2 & 1405.1 \\
\hline $\begin{array}{l}\text { Labour force (Active population), } \\
\text { total }\end{array}$ & 716.5 & 880.1 & 670.2 & 861.6 & 634.0 & 871.7 \\
\hline Employed & 592.7 & 707.1 & 567.3 & 709.7 & 521.1 & 676.8 \\
\hline Hired & 448.6 & 461.0 & 431.3 & 448.3 & 396.9 & 408.2 \\
\hline Self-employed & 144.1 & 245.4 & 135.9 & 260.9 & 124.0 & 267.9 \\
\hline Not-identified worker & 0.0 & 0.7 & 0.0 & 0.4 & 0.2 & 0.7 \\
\hline Unemployed & 123.8 & 173.0 & 103.0 & 151.9 & 112.9 & 194.9 \\
\hline Population outside the labour force & 898.0 & 528.8 & 937.2 & 562.8 & 972.2 & 533.4 \\
\hline Unemployment rate, percentage & 17.3 & 19.7 & 15.4 & 17.6 & 17.8 & 22.4 \\
\hline $\begin{array}{llr}\text { Labour force } & \text { participation rate } \\
\text { (Economic } & \text { activity rate), } \\
\text { percentage } & & \end{array}$ & 44.4 & 62.5 & 41.7 & 60.5 & 39.5 & 62.0 \\
\hline Employment rate, percentage & 36.7 & 50.2 & 35.3 & 49.8 & 32.4 & 48.2 \\
\hline
\end{tabular}

Source:National Statistics Office of Georgia

Also noteworthy is the fact that in 2019 , the average wage of women was $63.81 \%$ of the average salary of men. (See Figure 3). 


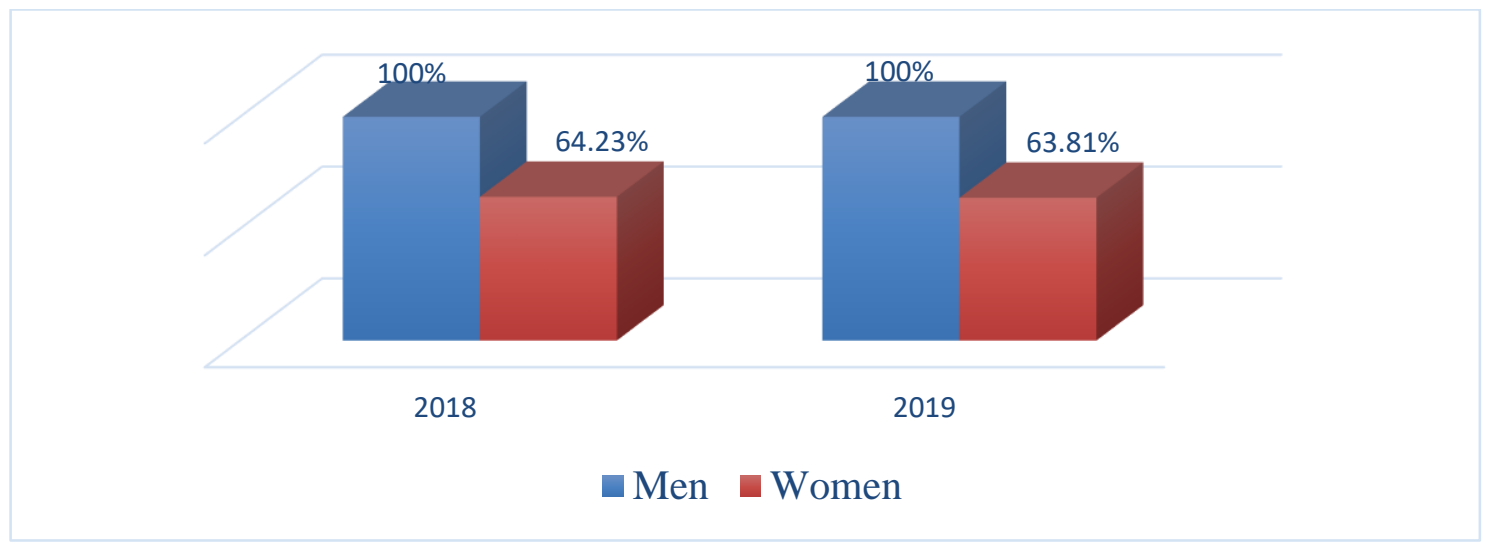

Figure 3. Average Monthly Wages by Sex (\%)

Source: National Statistics Office of Georgia

We have discussed the roles of four major theoretical models of organizational behavior, namely: autocratic, custodial, supportive, and collegial. The choice of organizational behavior model is determined by multiple factors. Organizational behaviour models are influenced by the priority philosophy, vision, mission, and goals of the organization and its managers. As well as external factors that also often lead to the application of a particular model.

Obviously, managers expect from their subordinates to deliver the best outcomes they can. One of the important functions of a manager is to determine the desired outcome in advance. However, it should always be kept in mind that in the pursuit of any purpose, the act of performing a particular task is accompanied by a behaviour characteristic of a particular individual that is related to many factors. It is the pre-determination and proper planning of these factors that increase the likelihood of achieving high performance quality. Performance-related behaviors for the manager include actions such as identifying problems, planning, organizing, and controlling employee performance and creating a motivating work environment for his/her employees.

In the late 1950s, Leon Festinger proposed the theory of Cognitive Dissonance, which explains the link between attitudes and behavior. Cognitive dissonance is any inconsistency that a person may see between two or more attitudes or attitudes and behaviors. Festinger argued that any form of inconsistency creates discomfort, which is why people try to reduce dissonance and hence discomfort. People will find a stable state where dissonance will be reduced to a minimum.

If employees do not work well or consistently, managers should investigate the problem. This requires constant monitoring of the relevant skills and abilities of the employees in order to reduce the likelihood of problems related to work performance. In addition, managers must be in constant search in order to 
constantly improve the skills and qualifications of employees in the era of modern rapid changes and innovations through various planning measures. Here, the issue of responsibility of both the manager and the employee is already unequivocally important; It is essential how the manager takes action to eliminate problems and how adequately the employee understands the performance-related problem. Therefore, it is necessary to provide continuous retraining, continuous teaching of employees.

We are interested in a management course towards staff because, as a result of the decisions they make, people form a special attitude towards specific events and processes, based on their professionalism, values, and traditions.

There is a cause-and-effect relationship between attitudes and behaviors. Therefore, attitude towards a particular action determines a particular behavior. At different times, in different countries, as a result of studies conducted by scientists, different conclusions have been made regarding the relationship between attitudes and behaviors. According to some studies, attitudes are not related to behavior or there is a weak connection between them. For example, if the facts of nepotism as a form of discrimination in the organization are revealed, eliminated and all employees are informed about it, of course, this will lead to staff activation, improvement of work performance and increase the effectiveness of measures to promote future career growth.

Studies carried out over the past twenty years (Lipovka, Islamgaleyev \& Badjanova, 2021; Gechbaia, Tchilaia, Goletiani \& Muskudiani, 2020; Paresashvili, Gurbanov, Gechbaia, Goletiani \& Edzgveradze, 2020) have proven that emotion is associated with governing phenomena such as justice, creativity, innovation, organizational culture, and organizational integrity.

We took an interest in the attitude of employees in the study-subject organizations towards management transparency.

We received quite a variety of answers about the management process going on as planned and transparently. A fairly high percentage (47\%) gave us a positive answer, however, at the same time we received quite a variety of answers regarding the governance course going on non-transparently and not as planned. which is probably due to ignorance or lack of transparency in the management process, or lack of interest in the final results, which is an unfavorable situation.

We became interested in studying the attitude of staff towards nepotism as a form of discrimination. It is unfortunate that in the condition of a course governed by justice and democratic principles, a fairly large proportion of respondents admitted that the use of systems to promote career growth takes place exactly in the condition of nepotism. 


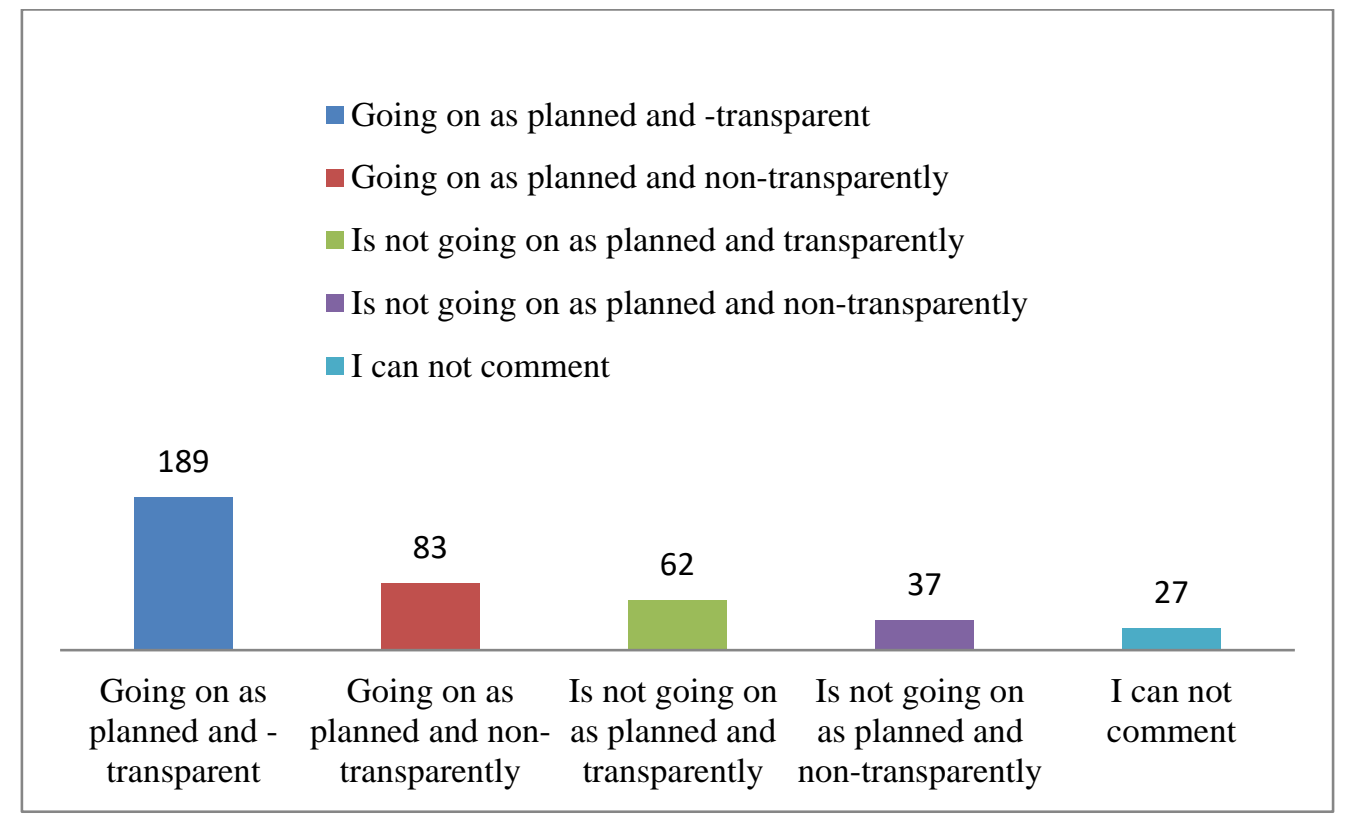

Figure 4. Do you think that the management process is planned and transparent? (Emphasis is placed on 4 main functions of management: planning, organizing, motivation, control)

Source: Own computations

Only a small proportion of respondents - 19\% denied the facts of nepotism, while $23 \%$ confidently confirm the implementation of continuous programs under the influence of nepotism, while the highest percentage - 58\% partially believe that the facts of nepotism take place, i.e. neither deny nor confirm it.

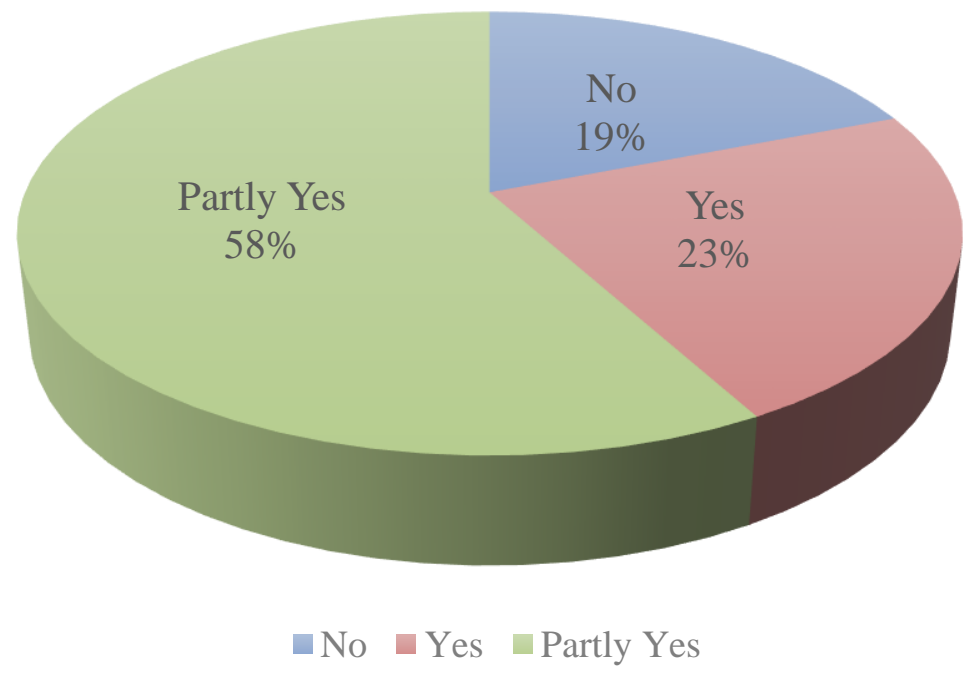

Figure 5. Are career growth support systems used in the conditions of nepotism?

Therefore, we think that this is a rather remarkable circumstance, as it categorically contradicts the 
principles of justice and democratic governance. (Figure 5)

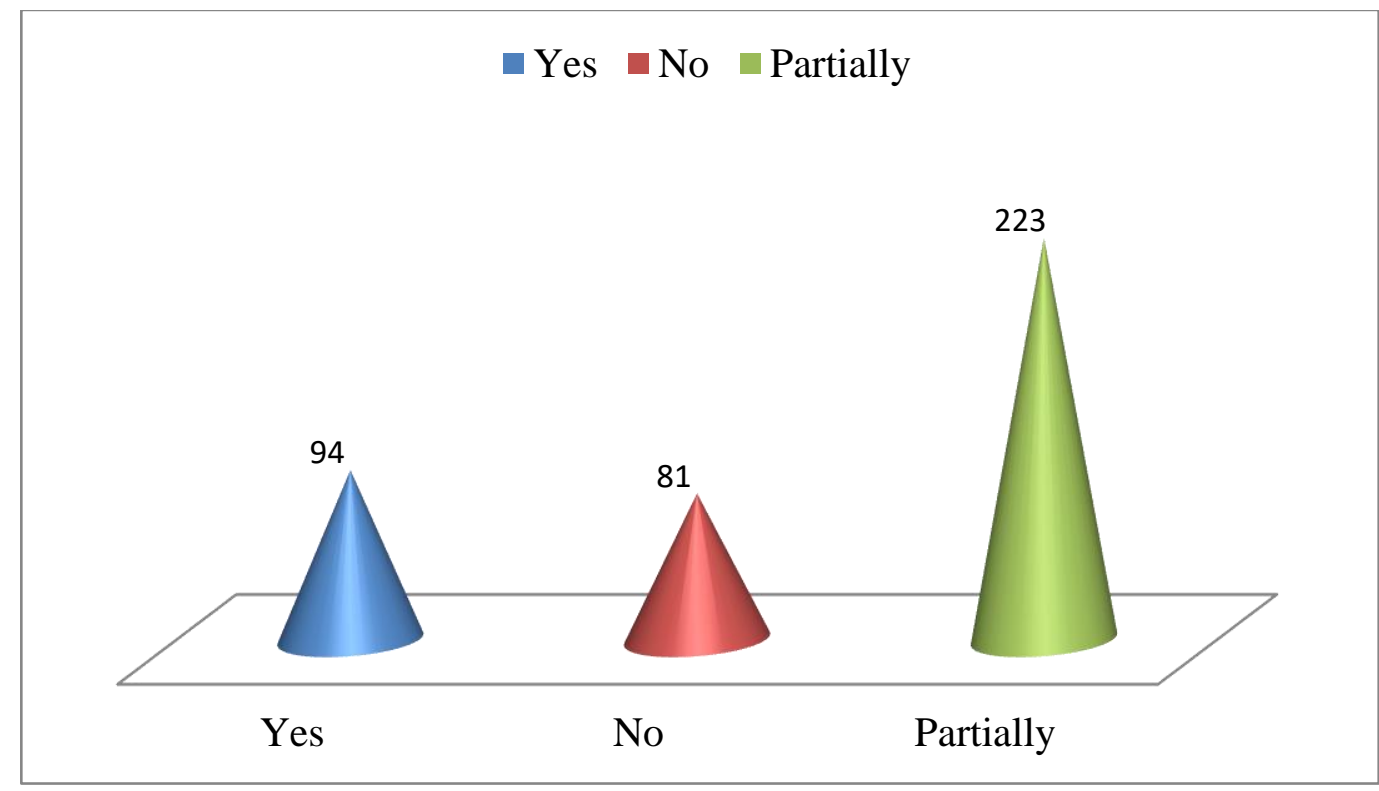

Figure 6. Attitudes towards the manifestation of nepotism in the process of continuous training (retraining) of employees in organizations

Source: Own computations

It was also interesting how the respondents assess the manifestation of nepotism in the process of continuous training (retraining) of employees in the organization.

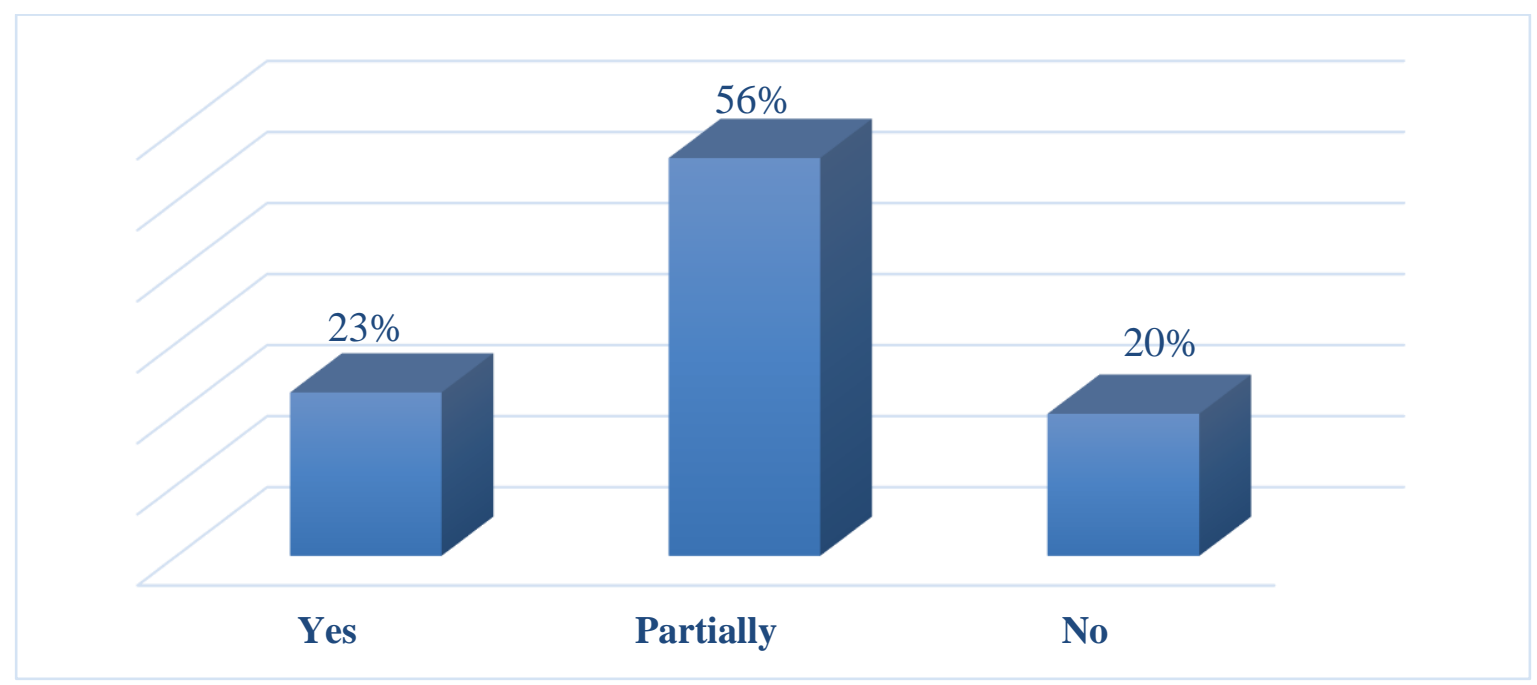

Figure7. Does the organization take care of an employee development? Source: Own computations

$23 \%$ of respondents think that managers implement a policy of continuous training of employees, while $56 \%$ of respondents believe that specific measures for the professional development of employees are taken 
only in part, while $20 \%$ think that nothing is done in this regard in organizations. (See Figure 7).

It is interesting to see how important managers and subordinates perceive the importance of the number of team members. Here, too, one of the answers requires a special analysis: the highest percentage of respondents believe that the number of team members is insignificant, what matters is the common goals; a high percentage was of the opinion that the number of team members should be determined by the nature of the problem; here, of course, the complexity of the problem is important, but the organizational form is built on certain patterns that must be taken into account by managers.

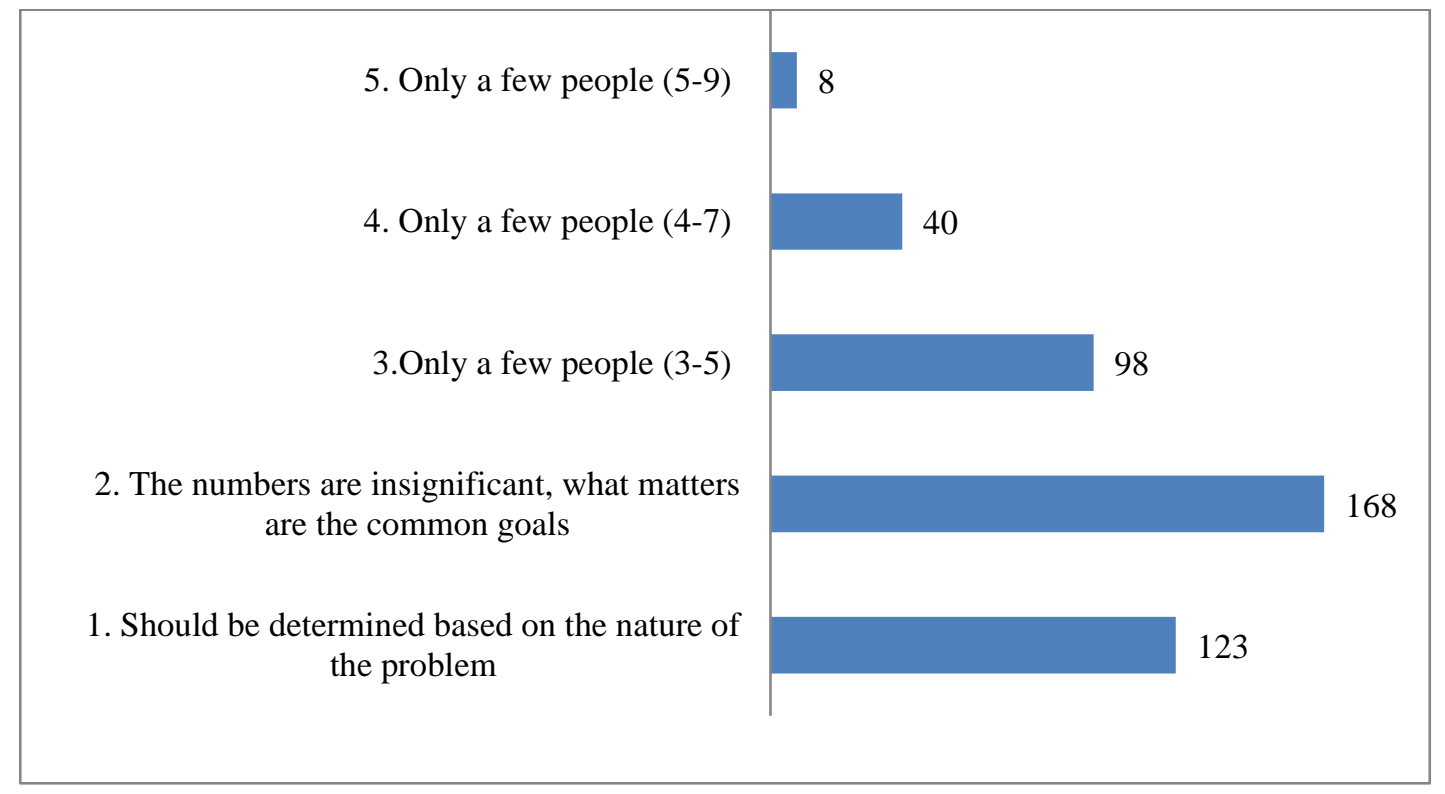

Figure 8. How many people should a team consist of? How many people should work on a particular problem? Source: Own computations

In connection to teams, it was important how staff perceived the importance of teams and groups in general, their impact on organizational behavior. The study found that $63 \%$ believe that groups and teams cannot change individual motives and attitudes to influence individual behavior in an organizational environment. Only $26 \%$ believe that teams can change the organizational climate. 


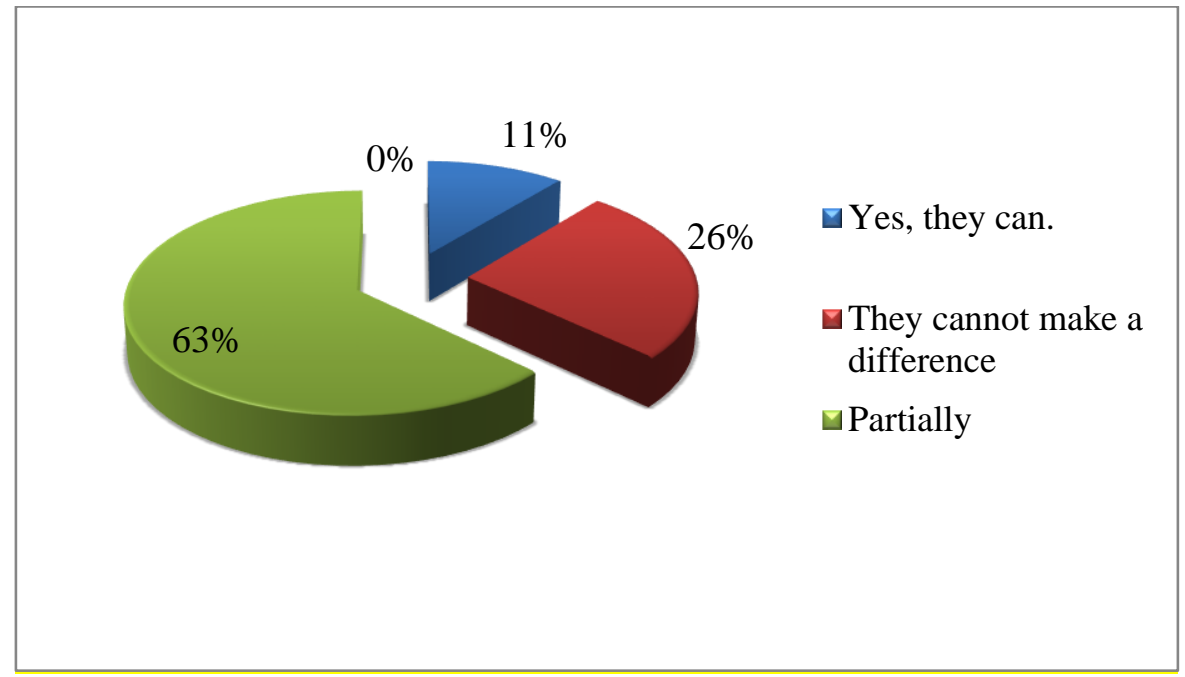

Figure 9. Influence of teams on individual motives and attitudes Source: Own computations

\section{CONCLUSION}

Given the modern challenges of managing an organization caused by the pandemic - the spread of Covid 19, the need to create an environment conducive to diversity in the workplace, accelerating the need for virtual organizations, flexible schedules, remote work, process digitization, and artificial intelligence have become apparent. This, together with solving the purely technical and technological issues, requires understanding and rejecting established stigmas, introducing an appropriate culture, raising awareness so that diversity brings not confrontation, confusion, and misunderstanding, but the best decision-making and synergistic effects based on a large selection of analytical variations.

Achieving employees' job satisfaction through high quality of work performed should become a key task for managers. In the work process, it is necessary to create an appropriate environment for innovation and creative views, which, as we see from the outcomes of the study, managers do not pay due attention to. It is unfortunate that leaders do not properly appreciate the importance of creating the desired environment in the work of the team and the organization as a whole. Workplace architecture and the work environment in general have a significant impact on team members' attitudes, including on the relationship and communication processes. Therefore, we need to keep in mind that modern and efficient workplace architecture (meaning physical environment) leads to improved communication between team members.

The development of state institutions, the growth of civil society activity, and especially the development of the judiciary system will play an important role in creating a diverse, non-discriminatory environment in Georgian organizations. 


\section{Conflict of interests}

The authors declare no conflict of interest.

\section{References}

Council of Europe. (26/02/1961). The European Social Charter. Council of Europe. Retrieved from https://www.coe.int/en/web/european-social-charter

Council of Europe. (4/11/1950). European Convention on Human Rights. Rome. Retrieved from https://www.echr.coe.int/documents/convention_eng.pdf

Faresashvili N., Keshelashvili G., (2010). Organizational Behavior, Tbilisi, Universal,

Gechbaia, B., Tchilaia, N., Goletiani, K., \& Muskudiani, Z. (2020). Ways and characteristics of employee motivation in modern conditions.

Gechbaia, B., \& Mushkudiani, Z. (2016). The experience of Japanese innovative management and its implementation capasity in Georgia. Global world:, 2, 35-38.

Gigauri, I. (2020A). Influence of Covid-19 Crisis on Human Resource Management and Companiesâ€тм Response: The Expert Study. International Journal of Management Science and Business Administration, 6(6), 15-24.

Gigauri, I. (2020B). Organizational Support to HRM in Times of the COVID-19 Pandemic Crisis. European Journal of Marketing and Economics, 3(3), 36-48.

Gigauri, I. (2021). Corporate Social Responsibility and COVID-19 Pandemic Crisis: Evidence From Georgia. International Journal of Sustainable Entrepreneurship and Corporate Social Responsibility (IJSECSR), 6(1), 30-47.

Gigauri, I., Gulua, E., \& Mushkudiani, Z. (2020). Current Advances In Digital Recruitment Of Human Resources And Its Potential For Companies. Current Advances In Digital Recruitment Of Human Resources And Its Potential For Companies (September 28, 2020). SEU \& Science.

Gulua, E. (2020A). Trends, Challenges and Orientations of Human Resource of Management. Innovative Economics And Management, Vol 7 No 1 (2020), pp. 51-67.

Gulua, E. (2020B). Preculiarities of Academic Staff Selection at Higher Education Insitutions. Innovative Economics And Management, Vol 7 No 1 (2)

Lipovka, A., Islamgaleyev, A., Badjanova, J. (2021). Innovation capability of women and men managers: evidence from Kazakhstan. Access to science, business, innovation in digital economy, ACCESS Press, 2(1): 91-102. https://doi.org/10.46656/access.2021.2.1(7)

Mullins, Laurie J. (2007). Management and Organizational behavior, New Jersey, Financial Times Management; 8 ap/Psc edition, ISBN-10 : 9780273708889 , ISBN-13 : 978-0273708889

Mushkudiani, Z., Gechbaia, B., Gigauri, I., \& Gulua, E. (2020). Global, economic and technological trends in human resource management development. Access Journal, 1(1), 53-60.

Mushkudiani, Z., \& Dzotsenidze, T. (2019). Modern human resource management trends. In Vth (Anniversary) International Scientific Conference Dedicated to the International Day of the Seafarers "Modern Maritime Technologies, Problems of Social-Economic Development and Ways for Solving Them (pp. 160-165).

Organizational Behavior, 13th (2013) by Mary Uhl-Bien, Richard N. Osborn, John R. Schermerhorn Jr.

Paresashvili, N., Gurbanov, N., Gechbaia, B., Goletiani, K., \& Edzgveradze, T. (2020). Significant issues of organizational conflict management. Economic and Social Development: Book of Proceedings, 457-464.

Robbins, St.P., Judge T.A. (2008). Organizational Behavior, New Jersey, Prentice Hall, 2008, 13 ${ }^{\text {th }}$ edition, The Legislative Herald of Georgia, available at: https://matsne.gov.ge/ka/document/view/1155567?publication=17 (accessed: February 2021)

Shonia, N., Mushkudiani, Z., Shalamberidze, K., \& Janelidze, N. (2018). Personal Management Challenges in Georgian Commercial Banks. Problems of Management in the 21st Century, 13(1). 
National Statistics Office of Georgia (Geostat) available at: https://www.geostat.ge/media/35684/Yearbook_2020.pdf. (accessed: February 2020)

United Nations. (16.12.1966). International Covenant on Civil and Political Rights. United Nations of Human Rights. Retrieved from https://www.ohchr.org/en/professionalinterest/pages/ccpr.aspx

United Nations. (16/12/1966). International Covenant on Economic, Social and Cultural Rights. United Nations Human Rights Office. Retrieved from https://www.ohchr.org/EN/ProfessionalInterest/Pages/CESCR.aspx

United Nations General Assembly. (10/12/1948). Universal Declaration of Human Rights. UN.

\section{About the authors}

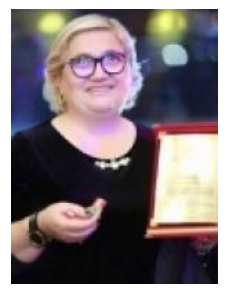

\section{Ketevan GOLETIANI}

$\mathrm{PhD}$ of Business Administration, Professor, Dean of Logistics faculty, Batumi Navigation Teaching University, Georgia. Research interests: HR management, innovation management, logistics and transport, economic growth. She has been taking participation in different international and local conferences.

ORCID ID: https://orcid.org/0000-0002-3074-4794

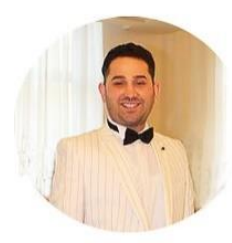

\section{Zurab MUSHKUDIANI}

Professor Mushkudiani is a leading researcher at Batumi Navigation Teaching University. He received his PhD from Akaki Tsereteli State University in 2015 and has worked on plenty of local and international educational projects. Also, he worked in Kutaisi City Hall as a PR senior specialist and maintained relationship with public. His specialties are Management, Finance and Education.

ORCID ID: https://orcid.org/0000-0003-0987-3564

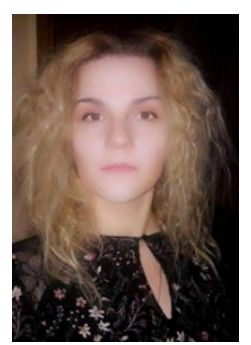

\section{Ekaterine GULUA}

$\mathrm{PhD}$ in Economics. Professor at Ivane Javakhishvili Tbilisi State University (TSU); Founder and CEO of Human Potential Management Laboratory, Faculty of Economics and Business, TSU: Her current research interests include Management, The Art of Management, Strategic Human Resource Management, Leadership, Talent Management, Human Potential Management, Management of Higher Education Institutions, Management of Organizational Culture, Structuring of Organizations.

ORCID ID: https://orcid.org/0000-0001-9484-093X

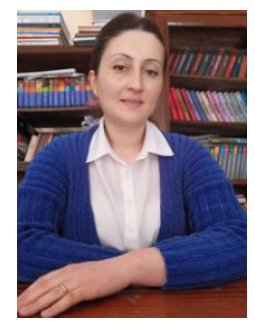

\section{Natela JANELIDZE}

$\mathrm{PhD}$ in Economics. Professor at Akaki Tsereteli State University. Her current research interests include Finances, Investment and Management. She has been taking part in different scientific and educational conferences.

ORCID ID: https://orcid.org/0000-0003-0125-8153 